\title{
Can transcutaneous recordings detect gastric electrical abnormalities?
}

\author{
B O Familoni, $\mathrm{K}$ L Bowes, Y J Kingma, K R Cote
}

\begin{abstract}
The ability of transcutaneous recordings of gastric electrical activity to detect gastric electrical abnormalities was determined by simultaneous measurements of gastric electrical activity with surgically implanted serosal electrodes and cutaneous electrodes in six patients undergoing abdominal operations. Transient abnormalities in gastric electrical activity were seen in five of the six patients during the postoperative period. Recognition of normal gastric electrical activity by visual analysis was possible $67 \%$ of the time and with computer analysis $95 \%$ of the time. Ninety four per cent of abnormalities in frequency were detected by visual analysis and $93.7 \%$ by computer analysis. Abnormalities involving a loss of coupling, however, were not recognised by transcutaneous recordings. Transcutaneous recordings of gastric electrical activity assessed by computer analysis can usually recognise normal gastric electrical activity and tachygastria. Current techniques, however, are unable to detect abnormalities in electrical coupling.
\end{abstract}

Human gastric electrical activity consists of recurrent regular depolarisations (slow waves) at 2.5 to 4 cycles per minute, and intermittent high frequency oscillations (spikes) that appear only in association with contractions. Slow waves begin high on the greater curvature and pass aborally towards the lesser curvature, accelerating as the pylorus is approached. As spikes can only occur during a portion of the slow wave cycle, slow waves are the ultimate determinant of the frequency and direction of propagation of contractions.

Slow waves are best recorded in vivo by surgically implanted electrodes. They have also been recorded by percutaneous and transmucosal techniques. ${ }^{1-4}$ The latter techniques are, however, noisy and recognition of gastric slow waves is possible during part of the recording time only. In some patients, successful recordings are not obtainable. Spikes are generally not seen on transcutaneous recordings.

In spite of the recording difficulties, abnormalities in gastric slow wave activity have been described using these techniques in patients with unexplained nausea and vomiting, ${ }^{5-7}$ anorexia nervosa,${ }^{8}$ gastroparesis, ${ }^{9-11}$ pregnancy related nausea, ${ }^{12}$ and motion sickness. ${ }^{13-15}$ Although comparing groups of patients with the same technique, as in these studies, lends credence to the existence of an abnormality in a particular group, the accuracy of transcutaneous electrogastrograms in diagnosing an abnormality in a single patient has not been determined.
This study was undertaken to determine the ability of transcutaneous electrical recordings to recognise various types of gastric slow wave abnormality. Implanted electrodes were used as our 'gold standard'. The postoperative period afforded the opportunity to study both normal and abnormal states of gastric slow waves. Abnormalities in these after surgery have been described using serosal electrodes. ${ }^{16-18}$ To exploit fully the potential of transcutaneous recordings, both visual analysis and extensive filtering and analysis on a digital computer were performed.

\section{Methods}

\section{ELECTROGASTROGRAPHIC METHODS}

Transcutaneous and serosal recordings of gastric slow waves were made simultaneously on six patients undergoing laparotomy for fundoplication, cholecystectomy, or bowel resection. The study had been approved by the ethics committee of the University of Alberta Hospitals in October 1986 and informed written consent was obtained from each subject before the procedure.

Three pairs of stainless steel wire electrodes $0.254 \mathrm{~mm}$ in diameter were implanted subserosally into the anterior surface of the antral wall, between $1.5 \mathrm{~cm}$ and $10.5 \mathrm{~cm}$ from the pylorus. The Teflon coated connecting wires were brought out through a 1 inch Penrose drain via a separate stab wound. Four ordinary Hewlett Packard electrocardiography electrodes (type 14445C) were placed on the skin in the epigastric region to form two pairs of bipolar recording electrodes. Each pair was aligned with the antral axis as previously described ${ }^{19}$ or as close to it as the surgical wounds permitted.

The implanted electrodes were connected to a Beckman dynograph recorder with a low cut off frequency of $0.017 \mathrm{~Hz}$ (1 cycle/minute) and a high cut off frequency of $30 \mathrm{~Hz}$ (1800 cycles/ minute). The cutaneous electrodes were connected to the dynograph at a low cut off frequency of $0.017 \mathrm{~Hz}$ (1 cycle/minute) and a high cut off frequency of $0.08 \mathrm{~Hz}(4 \cdot 8$ cycles/minute). The cut off frequency of $0.08 \mathrm{~Hz}$ was necessary to ensure rejection of electrocardiographic artefacts from the transcutaneous recording. The slope of this first order filter, however, was quite gentle ( $6 \mathrm{~dB} /$ octave). The attenuation at the cut off frequency $(4.8 \mathrm{cpm})$ was $-3 \mathrm{~dB}$ (or a factor of 0.71 ), and the attenuation of a signal at $9.6 \mathrm{cpm}$ was still only $-6 \mathrm{~dB}$ (or a factor of 0.5 ).

The signals at the dynograph amplifier outputs were sampled at a rate of $2 \mathrm{~Hz}$ and stored on an IBM pc AT computer via a Lab Master 20000912 bit, 8 channel A to D converter. 
Recording was started in the recovery room and continued for up to 120 hours.

\section{ANALYSIS OF RECORDINGS}

All channels were subjected to both visual and computer analysis. The recorded signals were visually inspected for regularity in the slow wave period, frequency, and presence of abnormalities. The transcutaneous recording was inspected blind - that is, without reference to the serosal recordings. The percentage of time during which the recorded signal was normal and the number and type of abnormalities recorded were determined. These were then compared with a similar individual analysis of the serosal recordings to determine the correlation and accuracy of the transcutaneous method.

We defined normal gastric slow waves in accordance with several previous reports of gastric slow waves in healthy people - that is, regular activity with a fundamental frequency between 2.0 and 4.5 cycles/minute. ${ }^{1341920}$ Both coupled (phaselocked) and uncoupled abnormalities were observed. The coupled abnormalities included tachygastria, irregular slow waves, and electrical 'shutdown'. Tachygastria was defined as stable slow wave with a frequency higher than $4.5 \mathrm{cpm}^{2561012}$ Irregular slow waves were characterised by variations of $10-60 \%$ in the period of successive cycles of the slow waves. An electrical 'shutdown' was assumed to occur when no slow waves were seen in any channel for 40 seconds or more (corresponding to a maximum slow wave frequency of less than $1.5 \mathrm{cpm}$ ). Two types of uncoupled (not phaselocked) gastric slow waves were seen. In the first type the different sites had different frequencies and the signals were irregular. In the second type the same frequency was evident at different sites, but the signals were not coupled.

Computer analysis consisted of sequential power spectrum analysis over successive 128 second $50 \%$ overlapping intervals and cross
(A)

$$
\text { (A) }
$$

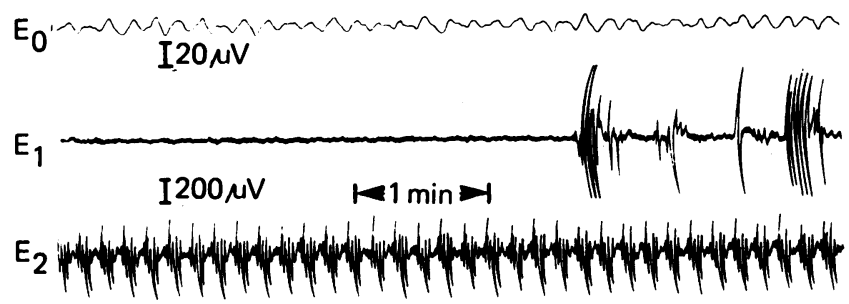

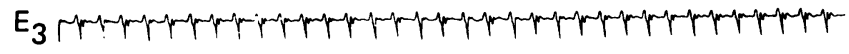

(c)

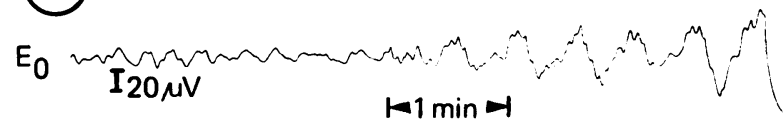

$E_{1}$

I200 MV

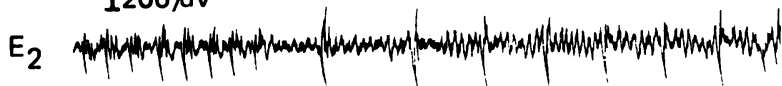

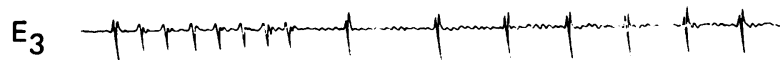

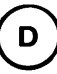

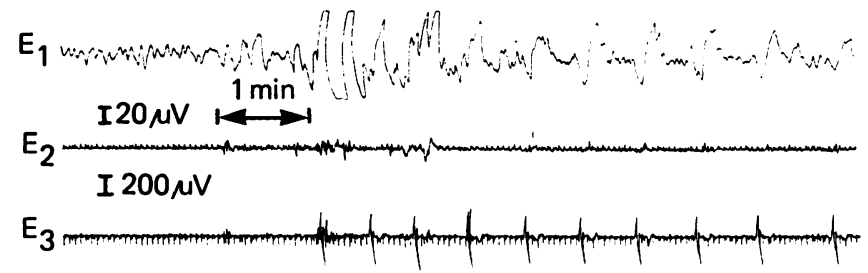

E)
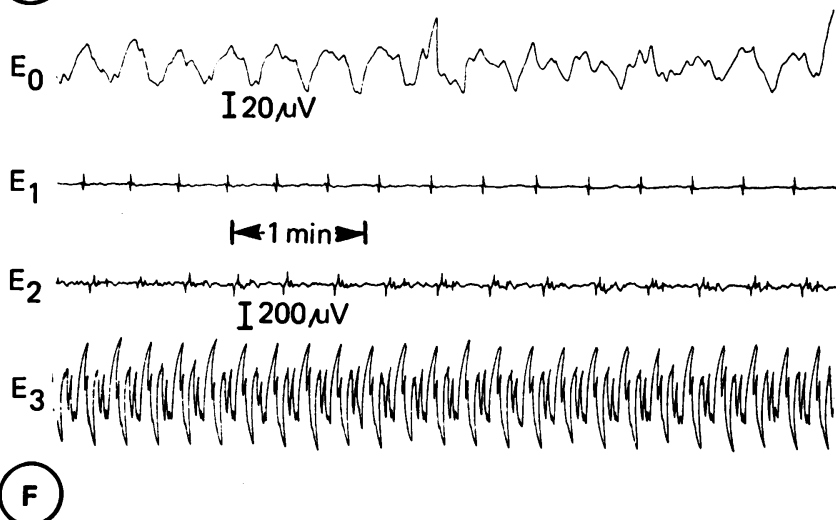

$E_{0} \underset{I 20 \mu V}{\operatorname{mon}}$

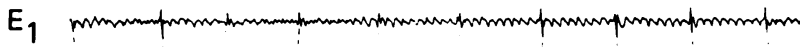

I $200 \mathrm{MV}$

$E_{2}$

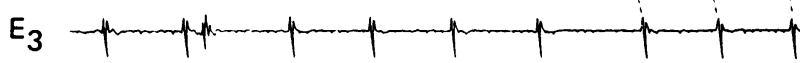

Figure 1: Gastric electrical activity recorded simultaneously by cutaneous $\left(E_{0}\right)$ and serosal $\left(E_{1}-E_{3}\right)$ electrodes.

(A) Normal gastric slow waves (GSW) $(2 \cdot 8 \mathrm{cpm})$ recorded by both cutaneous and serosal electrodes.

(B) Tachygastria $(6 \mathrm{cpm})$ evident in both serosal and cutaneous records. $E_{1}$ has become loosely implanted and displays low signal to noise ratio.

(C) Irregular, but coupled, GSW evident in both serosal and cutaneous records.

(D) GSW 'shutdown' marked by absence of discernible signal in serosal and cutaneous electrodes followed by return of slow waves in cutaneous and one serosal electrode. The third serosal electrode in this patient had previously broken off.

(E) Uncoupled regular GSW with different frequencies in different parts of the stomach $\left(E_{1}, E_{2} 2 \cdot 9 \mathrm{cpm}, E_{3} 4 \cdot 2 \mathrm{cpm}\right)$. The cutaneous electrode ignores the

frequency of $E_{3}$ but accurately reflects $E_{1}$ and $E_{2}$.
(F) Uncoupled and irregular $G S W$. The boken lines in the serosal recording link successive slow waves in adjacent channels. The variable pattern of these lines indicates uncoupling. The cutaneous electrode's signal does not accurately reflect the actual gastric events. 
correlation. Fast Fourier transform with a Hamming window were calculated for the 256 samples in each time frame to determine the signal frequencies. Power spectrum analysis breaks down a signal, permitting determination of frequencies of any rhythmical activities even if the signal is corrupted by random noise; ${ }^{21}$ a difference in the fundamental frequencies of any two signals indicates that they are not phase locked. Cross correlation determines which frequencies, if any, are common to two given signals. This method was employed to determine whether the slow wave was coupled or not. ${ }^{20}$

Periods of nursing care or patient movement as marked on the recording paper by the nursing staff were excluded from the analysis. The implanted electrodes were removed with the drain when the latter was no longer needed 72 to 120 hours after its insertion.

\section{Results}

\section{SEROSAL RECORDINGS}

Serosal electrodes gave excellent recordings of gastric slow waves. Out of a total recording duration of 491.9 hours, 7.3 hours were unusable because of motion artefacts from nursing care. Data analysis was restricted to the remaining 484.6 hours of recording.

Normal slow wave was recorded for most of the recording time $(76 \cdot 84 \%)$. In the recovery

TABLE I Gastric slow wave (GSW) abnormalities recorded at $(A)$ serosal electrodes, $(B)$ cutaneous electrodes, and $(C)$ those recorded simultaneously at both sites

\begin{tabular}{lccr}
\hline & $\begin{array}{l}\text { No of } \\
\text { episodes }\end{array}$ & $\begin{array}{l}\text { Duration(min) } \\
(\text { mean }(S D))\end{array}$ & \multicolumn{1}{c}{$\begin{array}{c}\text { Total } \\
(\text { hrs })\end{array}$} \\
\hline (A) Serosal electrodes & & & \\
Tachygastria & 131 & $45 \cdot 9(74 \cdot 3)$ & $100 \cdot 22$ \\
Irregular GSW & 11 & $7(2 \cdot 6)$ & $1 \cdot 28$ \\
Electrical shutdown & 5 & $3 \cdot 5(2 \cdot 6)$ & $0 \cdot 29$ \\
Uncoupled I & 4 & $217 \cdot 3(92 \cdot 4)$ & $14 \cdot 49$ \\
Uncoupled II & 5 & $5 \cdot 2(2 \cdot 7)$ & $0 \cdot 43$ \\
Total & 156 & & $116 \cdot 71$ \\
(B) Cutaneous electrodes & 127 & $47(74 \cdot 9)$ & $99 \cdot 48$ \\
Tachygastria & 12 & $7 \cdot 3(2 \cdot 3)$ & $1 \cdot 46$ \\
Irregular GSW & 3 & $3 \cdot 6(2 \cdot 7)$ & $0 \cdot 18$ \\
Electrical shutdown & 0 & $0(0)$ & $0 \cdot 00$ \\
Uncoupled I & 0 & $0(0)$ & $0 \cdot 00$ \\
Uncoupled II & 142 & & $101 \cdot 12$ \\
Total & 122 & $46 \cdot 3(74 \cdot 6)$ & $94 \cdot 14$ \\
(C) Abnormalities recorded simultaneously by both methods & \\
Tachygastria & 9 & $7 \cdot 1(2 \cdot 2)$ & $1 \cdot 07$ \\
Irregular GSW & 9 & $3 \cdot 6(2 \cdot 7)$ & $0 \cdot 18$ \\
Electrical shutdown & 3 & $0(0)$ & $0 \cdot 00$ \\
Uncoupled I & 0 & $0(0)$ & $0 \cdot 00$ \\
Uncoupled II & 0 & & $95 \cdot 39$ \\
Total & 134 & &
\end{tabular}

room ( 0 to 1 hour postoperatively), the slow waves in all six patients remained regular, with a mean (SD) frequency $2.91(0.48) \mathrm{cpm}(0.049$ $(0 \cdot 008) \mathrm{Hz}$ ) (Fig 1A).

Slow wave abnormalities were seen in five patients shortly after the recovery room period; the abnormalities lasted up to $10 \cdot 75(4.61)$ hours postoperatively in four, and persisted until the implanted electrodes were removed (120 hours) in the fifth. We had suspected from intraluminal and transcutaneous measurements before the operation that this fifth patient had gastric electrical abnormalities.

One hundred and fifty six separate episodes of slow wave abnormalities were recorded from the serosa (Table I). Coupled (tachygastria, irregular slow wave, electrical 'shutdown') and uncoupled abnormalities were observed. Tachygastria was the commonest abnormality detected in both the transcutaneous and gastric recordings (Fig 1B). Eleven episodes of irregular slow waves lasting an average of seven minutes were recorded (Fig 1C). Electrical 'shutdown' was recorded five times by the serosal electrodes with an average duration of 3.5 (2.6) minutes (Fig 1D).

Nine episodes of uncoupled activity were recorded. In four there were different frequencies at separate sites (Figs $1 E$ and F).

\section{CUTANEOUS RECORDINGS}

Cutaneous recordings reflected actual gastric electrical events poorly (Table II). Normal slow waves were recognised by cutaneous electrodes only $67 \%$ of the time. Surprisingly, tachygastria was recognised more often $(91 \%$ of the time). Irregular electrical activity and electrical 'shutdown' pauses were often not recognised; they were recognised at the cutaneous recording only $63 \%$ and $67 \%$ of the time respectively. Uncoupled gastric electrical events were not recognised in any cutaneous recording. During uncoupling cutaneous electrodes did not accurately reflect gastric slow wave (Fig $1 E$ and $F$ )

Computer analysis dramatically improved the ability of transcutaneous recordings to detect coupled gastric events (Table II). For instance, normal slow waves were recognised $95 \%$ of the recording time. Irregular slow waves and electrical 'shutdown' were not diagnosed with greater precision, however, and uncoupling was again not recognised. Detection of irregular slow

TABLE II Accuracy of transcutaneous recordings in diagnoses of normal and abnormal gastric slow wave (GSW) (visual analyses)

\begin{tabular}{|c|c|c|c|c|c|c|c|}
\hline \multirow{2}{*}{\multicolumn{2}{|c|}{$\begin{array}{l}\text { Gastric slow wave activity } \\
\text { (Serosal electrodes) (hrs) }\end{array}$}} & \multicolumn{6}{|c|}{ Cutaneous electrical recording (\%) } \\
\hline & & Normal & Undecipherable & Tachygastria & $\begin{array}{l}\text { Irregular } \\
\text { GSW }\end{array}$ & $\begin{array}{l}\text { Electrical } \\
\text { shutdown }\end{array}$ & Uncoupled \\
\hline $\begin{array}{l}\text { (A) Visual analyses } \\
\text { Normal } \\
\text { Tachygastria } \\
\text { Irregular GSW } \\
\text { Electrical shutdown } \\
\text { Uncoupled I } \\
\text { Uncoupled II } \\
\text { (B) Computer analyses }\end{array}$ & $\begin{array}{c}369 \cdot 05 \\
100 \cdot 4 \\
1 \cdot 4 \\
0 \cdot 3 \\
15 \cdot 1 \\
0 \cdot 4\end{array}$ & $\begin{array}{l}67 \cdot 01 \\
0 \\
0 \cdot 71 \\
0 \\
35 \cdot 1 \\
0\end{array}$ & $\begin{array}{c}31 \cdot 02 \\
9 \cdot 11 \\
35 \cdot 71 \\
26 \cdot 67 \\
43 \cdot 71 \\
97 \cdot 5\end{array}$ & $\begin{array}{l}1.96 \\
90 \cdot 89 \\
1.43 \\
13 \cdot 33 \\
20 \cdot 53 \\
2.5\end{array}$ & $\begin{array}{l}0 \cdot 01 \\
0 \\
62 \cdot 86 \\
0 \\
0 \cdot 66 \\
0\end{array}$ & $\begin{array}{l}0 \\
0 \\
0 \\
66 \cdot 67 \\
0 \\
0\end{array}$ & $\begin{array}{l}0 \\
0 \\
0 \\
0 \\
0 \\
0\end{array}$ \\
\hline $\begin{array}{l}\text { Normal } \\
\text { Tachygastria } \\
\text { Irregular GSWW } \\
\text { Electrical'shutdown } \\
\text { Uncoupled I } \\
\text { Uncoupled II }\end{array}$ & $\begin{array}{c}367 \cdot 88 \\
100 \cdot 22 \\
1 \cdot 29 \\
0 \cdot 29 \\
14 \cdot 25 \\
0 \cdot 43\end{array}$ & $\begin{array}{c}95 \cdot 44 \\
0 \\
0 \cdot 78 \\
0 \\
22 \cdot 46 \\
0\end{array}$ & $\begin{array}{l}3 \cdot 85 \\
5 \cdot 82 \\
15 \cdot 5 \\
27 \cdot 59 \\
57 \cdot 54 \\
97 \cdot 67\end{array}$ & $\begin{array}{r}0 \cdot 71 \\
93 \cdot 93 \\
0 \cdot 73 \\
10 \cdot 34 \\
18.95 \\
2.33\end{array}$ & $\begin{array}{l}0 \\
0.25 \\
82.95 \\
0 \\
1.05 \\
0\end{array}$ & $\begin{array}{l}0 \\
0 \\
0 \\
62 \cdot 07 \\
0 \\
0\end{array}$ & $\begin{array}{l}\mathbf{0} \\
\mathbf{0} \\
\mathbf{0} \\
\mathbf{0} \\
\mathbf{0} \\
\mathbf{0}\end{array}$ \\
\hline
\end{tabular}


(A)
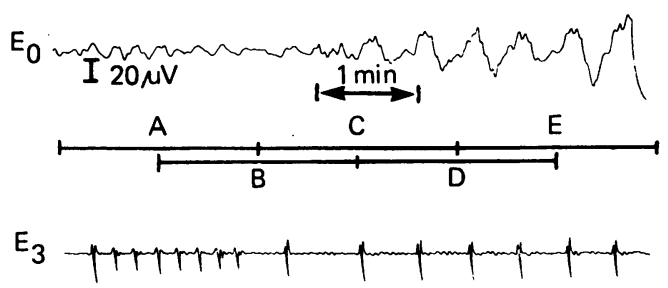

(B)

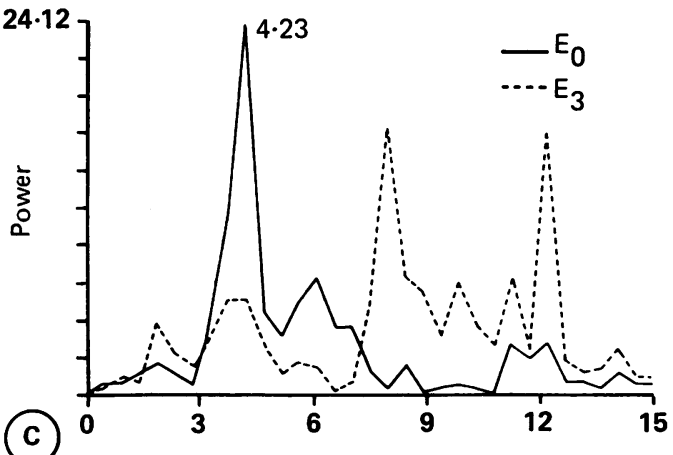

(E)

(D)
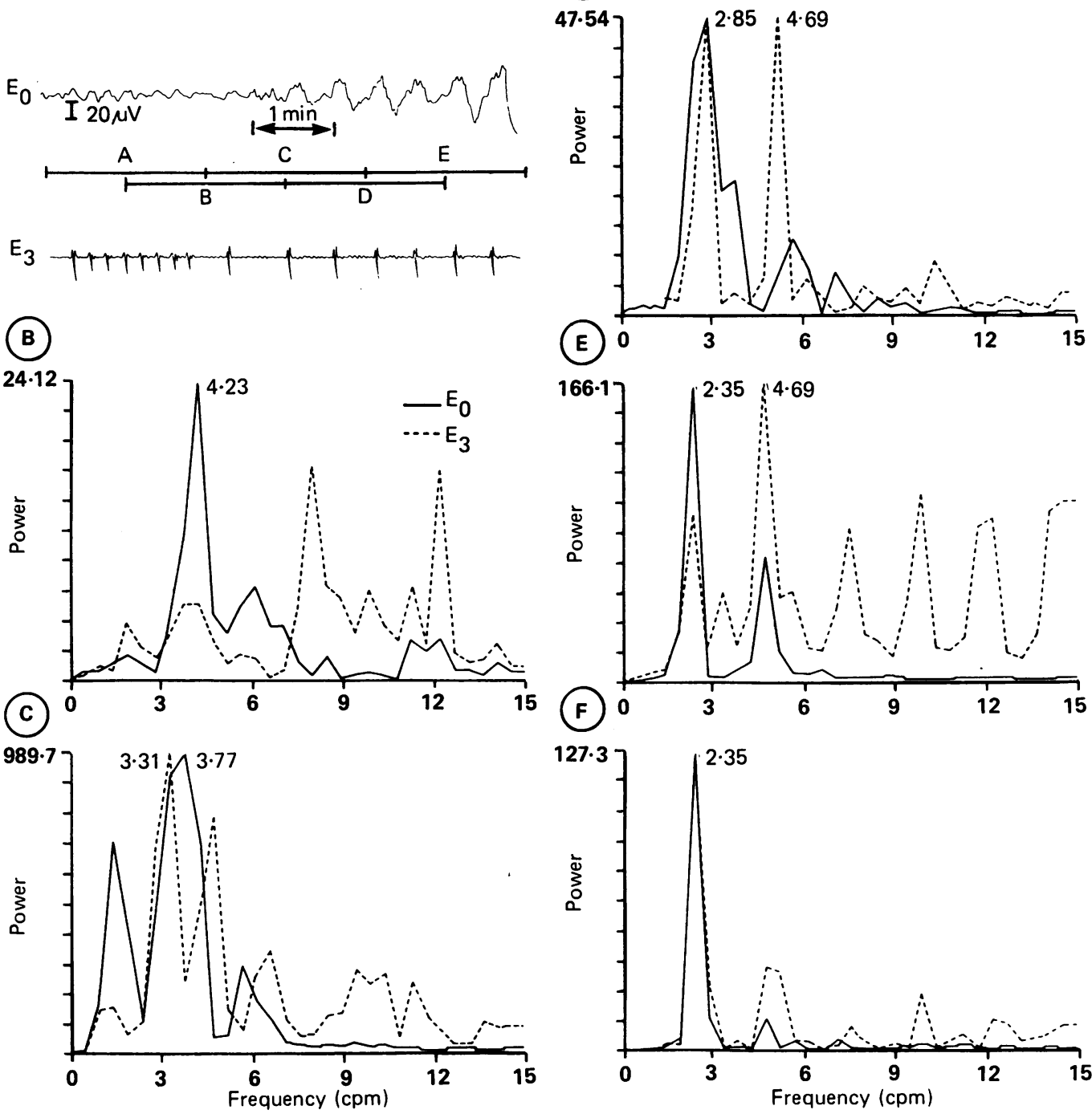

Figure 2: (A) Cutaneous $\left(E_{0}\right.$ and serosal $\left(E_{3}\right)$ recordings of gastric slow wave (GSW) during a period of shifting frequencies. Sequential frequency power spectra of 128 second overlapping intervals $(A, B, C, D, E)$ of $E_{0}$ and $E_{3}$ were obtained and are illustrated in $2 A-F$. The amplitude scales are arbitrary. The major peaks are labelled with their frequencies.

(B) $E_{0}$ and $E_{3}$ have the fundamental frequency of $4.23 \mathrm{cpm}$ in common. The term fundamental is the repetition frequency of a signal. When this periodic signal is highly non-sinusoidal in shape the harmonic content increases - that is, integrar multiples or overtones of the fundamental frequency are seen..$^{25}$ Note that the harmonics of $E_{3}$ are prominent and the fundamental is small.

(C) $E_{0}$ and $E_{3}$ deviate from the common frequency in $B$. The wide peak of $E_{0}$ at $3 \cdot 77 \mathrm{cpm}$ indicates shifting frequencies.

(D) $E_{0}$ and $E_{3}$ are both settling to a lower common frequency.

( $E$ and $F) E_{0}$ and $E_{3}$ have a sharp fundamental peak in common at $2.35 \mathrm{cpm}$.

waves by power spectrum analysis was contingent on the observer detecting particular trends in sequential frames of the power spectra and was therefore quite subjective. For example, the variations in frequency of the irregular slow waves (Fig 2) resulted in an unstable frequency pattern in the power spectra analysis as shown in Figure 2B to $\mathrm{F}$. At the height of the transition, two distinct slow wave frequencies that were not harmonically related $(2.85$ and $4.69 \mathrm{cpm})$ were seen (Fig 2D).

When the transcutaneous signal was normal,

TABLE III Gastric slow waves (GSW) during various patterns of transcutaneous recordings

\begin{tabular}{|c|c|c|c|c|c|c|c|}
\hline \multirow{2}{*}{\multicolumn{2}{|c|}{ Cutaneous recording (hrs) }} & \multicolumn{6}{|c|}{ Gastric electrical activity (\%) } \\
\hline & & Normal & Tachygastria & $\begin{array}{l}\text { Irregular } \\
\text { GSW }\end{array}$ & $\begin{array}{l}\text { Electrical } \\
\text { shutdown }\end{array}$ & $\begin{array}{l}\text { Uncoupled } \\
I\end{array}$ & $\begin{array}{l}\text { Uncoupled } \\
\text { II }\end{array}$ \\
\hline $\begin{array}{l}\text { (A) Visual analyses } \\
\text { Normal } \\
\text { Undecipherable } \\
\text { Tachygastria } \\
\text { Irregular GSW } \\
\text { Electrical shutdown } \\
\text { Uncoupled } \\
\text { (B) Computer analyses }\end{array}$ & $\begin{array}{r}251 \cdot 04 \\
127 \cdot 81 \\
103 \cdot 96 \\
0.97 \\
0 \cdot 17 \\
0\end{array}$ & $\begin{array}{l}94 \cdot 8 \\
88 \cdot 2 \\
13 \\
4 \cdot 12 \\
0 \\
0\end{array}$ & $\begin{array}{c}3 \\
7 \cdot 4 \\
81 \cdot 5 \\
2 \cdot 06 \\
23 \cdot 53 \\
0\end{array}$ & $\begin{array}{c}0 \cdot 6 \\
0 \cdot 2 \\
0 \cdot 3 \\
71 \cdot 13 \\
0 \\
0\end{array}$ & $\begin{array}{l}0 \\
0 \cdot 1 \\
0 \cdot 02 \\
0 \\
70 \cdot 59 \\
0\end{array}$ & $\begin{array}{c}2 \cdot 1 \\
4 \cdot 1 \\
4 \cdot 9 \\
22 \cdot 68 \\
0 \\
0\end{array}$ & $\begin{array}{l}0 \\
0 \cdot 1 \\
0 \cdot 27 \\
0 \\
11 \cdot 76 \\
0\end{array}$ \\
\hline $\begin{array}{l}\text { Normal } \\
\text { Undecipherable } \\
\text { Tachygastria } \\
\text { Irregular GSW } \\
\text { Electrical shutdown } \\
\text { Uncoupled }\end{array}$ & $\begin{array}{c}341 \cdot 06 \\
39 \cdot 2 \\
103 \cdot 62 \\
0 \cdot 63 \\
0 \cdot 26 \\
0\end{array}$ & $\begin{array}{c}97 \cdot 34 \\
76 \cdot 52 \\
5 \cdot 4 \\
26 \cdot 98 \\
3 \cdot 85 \\
0\end{array}$ & $\begin{array}{r}1 \cdot 55 \\
6 \cdot 89 \\
88 \cdot 88 \\
1 \cdot 59 \\
11 \cdot 54 \\
0\end{array}$ & $\begin{array}{c}0.02 \\
1 \cdot 73 \\
0 \cdot 21 \\
47 \cdot 62 \\
0 \\
0\end{array}$ & $\begin{array}{l}0 \\
0 \cdot 05 \\
0 \\
0 \\
65 \cdot 38 \\
0\end{array}$ & $\begin{array}{c}1 \cdot 08 \\
14 \cdot 29 \\
5 \cdot 31 \\
17 \cdot 46 \\
0 \\
0\end{array}$ & $\begin{array}{l}0 \\
0 \cdot 51 \\
0 \cdot 19 \\
6 \cdot 35 \\
19 \cdot 23 \\
0\end{array}$ \\
\hline
\end{tabular}




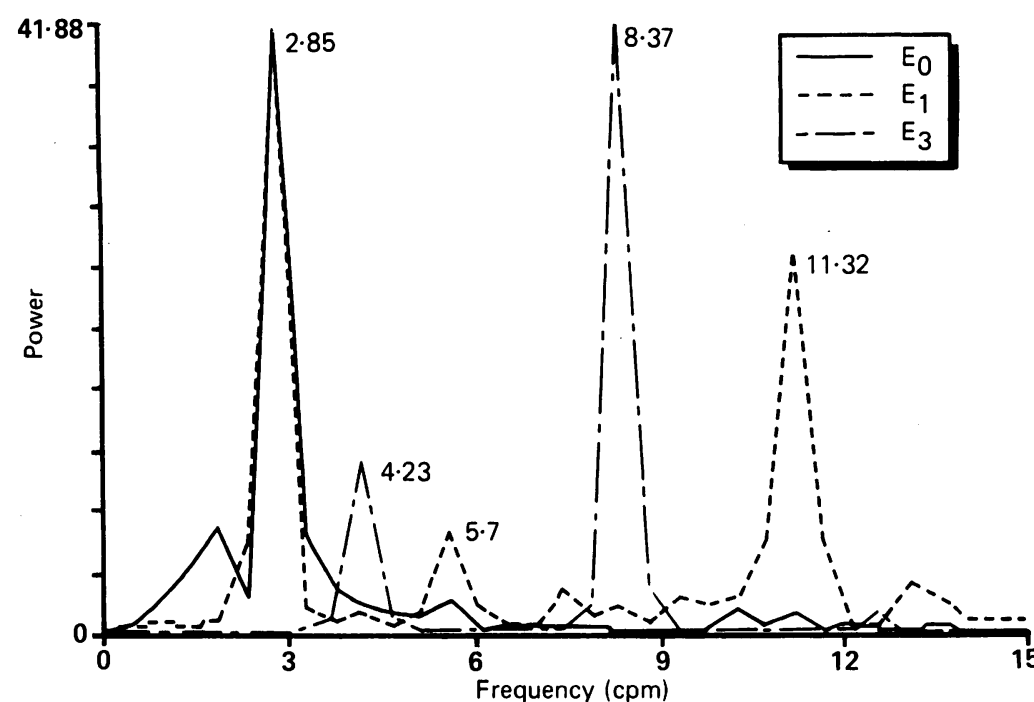

Figure 3: Frequency power spectra of uncoupled regular electrical activity (Fig 1A). The cutaneous recording $E_{0}$ duplicated $E_{1}$, but ignored $E_{3} . E_{0}$ (cutaneous) and $E_{1}$ (serosal) exhibit the same strong fundamental frequency at $2.85 \mathrm{cpm} . E_{1}$ also contains several harmonics of this frequency. Serosal electrode $E_{3}$ however does not contain a component at $2 \cdot 85 \mathrm{cpm}$, but instead it has peaks at $4 \cdot 23 \mathrm{cpm}$.
Cutaneous recording can recognise $67 \%$ of normal gastric slow waves, $90 \%$ of tachygastria, $62 \%$ of irregularities in gastric electrical activity, and $67 \%$ of electrical 'shutdown'. If computer analysis is used these figures alter to $95 \%, 93 \%$, $82 \%$, and $62 \%$ respectively.

When cutaneous electrodes indicate a normal record they are accurate $95 \%$ of the time. A cutaneous recording of tachygastria is confirmed $82 \%$ of the time. Irregularities in slow waves and electrical 'shutdown' are accurate reflections of the true situation in 71 and $70 \%$ of the time. These figures are altered by computer analysis to $97 \%, 89 \%, 47 \%$, and $65 \%$.

Cutaneous records, however, cannot pick up uncoupling (Fig 3). Homogeneous linear conducting models of the human torso ${ }^{21-23}$ suggest that this is probably because electrogastrographs represent the summation of all activity and reflect the major mass of tissue. If most of the stomach is normally coupled, a regular record at a normal or fast frequency is obtained (Fig 1E) and a very significant underlying gastric disorder could be missed.

Computer analysis is obviously of considerable value in interpreting gastric electrical activity recordings. Without it $26 \%$ of records are undecipherable, whereas with it only $8 \%$ cannot be deciphered. With computer analysis, transcutaneous gastric electrical activity is in certain instances of definite value. If a normal recording is obtained it is highly likely that the patient's gastric slow wave activity is normal. Similarly, tachygastria will be an accurate reflection of the situation in the stomach in nine out of 10 subjects. The commonest abnormality reported in patients with gastric electrical abnormalities is, in fact, tachygastria..$^{5-810}$ It might be asked whether tachygastria is of much functional importance. Although a frequency of 6 per minute indicates a change in the state of the gastric oscillators, it is not established that contractions occurring at a frequency of 6 per minute are less efficient than those occurring at 3 per minute.

The important abnormalities in gastric slow wave activity are probably those involving an orad spread or a loss of coupling of the electrical slow waves. As gastric slow wave determines the frequency and direction of propagation of contractions, these abnormalities could have a profound effect on gastric contractions and emptying. If the gastric oscillators were coupled in an orad direction, contractions could only move in that direction resulting in delayed emptying and possibly vomiting. A loss of coupling in the antrum would produce incoordinated contractions and retard gastric emptying considerably. Unfortunately, this study indicates that neither of these abnormalities can be accurately assessed with transcutaneous recordings. The practical value of the test is, therefore, severely limited. Future endeavours should focus on techniques for improving non-invasive recordings of gastric electrical activity before too much reliance is placed on recordings made using current techniques.

We offer a final note of caution. Often a record is noisy. It is tempting to interpret apparent irregularities in transcutaneous recording to be a 
true reflection of real gastric electrical activity. Such interpretations could be dangerous, particularly if they led to therapeutic interventions.

This work was supported in part by grant MA-5946 from the Medical Research Council of Canada.

1 Hamilton JW, Bellahsene BE, Reichelder M, Webster JG, Bass $P$. Human electro Bass $P$. Human electrogastrograms: comparison of

2 Abell TL, Malagelada J-R. Glucagon evoked gastric dysrhythmias in humans shown by an improved electrogastrographic technique. Gastroenterology 1985; 88: 193240.

3 Bellahsene BE, Hamilton JW, Webster JG, Bass P, Reichfelder $M$. An improved method for recording and analyzing the electrical activity of the human stomach. IEEE Trans Biomed Eng 1985; 32: 911-5.

4 Familoni BO, Kingma YJ, Bowes KL. A study of transcutaneous and intraluminal measurements of gastric electrical activity in humans. Med Biol Eng Comput 1987; 25: electrical $397-402$.

5 Geldof H, Van Der Schee EJ, Van Blankenstein M, Grashuis JL. Electrogastrographic study of gastric myoelectrical activity in patients with unexplained nausea and vomiting Gut 1986; 27; 799-808.

6 You CH, Chey WY. Study of electromechanical activity of the stomach in humans and in dogs with particular attention to tachygastria. Gastroenterology 1980; 86: 1460-8.

7 You CH, Lee KY, Chey WY, Mengur R. Electrogastrographic study of patients with unexplained nausea, bloating and vomiting. Gastroenterology 1980; 79: 311-4.

8 Abell TL, Malagelada J, Lucas AR, et al. Gastric electromechanical and neurohormonal function in anorexia nervosa. Gastroenterology 1987; 93: 958-65.

9 Abell TL, Camilleri M, Malagelada J-R. High prevalence of gastric electrical dysrhythmias in diabetic gastroparesis. gastric electrical dysrhythmias
Gastroenterology 1985; 88: 1299.

10 Pfister CJ, Hamilton JW, Nagel N, Bass P, Webster JG, Tompkins WJ. Use of spectral analysis in the detection of normal and diabetic subjects. IEEE Trans Biomed Eng 1988; 35: 935-41.
11 Telander RL, Morgan KG, Kreulen DL, Schmalz PF, Kelly KA, Szurszewski JK. Human gastric atony with tachygastria and gastric retention. Gastroenterology 1978; 75: 497 501 .

12 Koch KL, Creasey GW, Dwey A, Vasey M, Stern RM. Gastric dysrhythmia and nausea of pregnancy [Abstract]. Dig Dis Sci 1987; 32: 909 .

13 Stern RM, Koch KL, Liebowitz HW, Lindblad IM, Shupert $\mathrm{CL}$, Stewart WR. Tachygastria and motion sickness. Aviat Space Environ Med 1985; 56: 1074-7.

14 Stern RM, Koch KL, Stewart WR, Lindblad IM. Spectral analysis of tachygastria recorded during motion sickness. Gastroenterology 1987; 92: 92-7.

15 Rague BW, Oman CM. Use of a microcomputer system for running spectral analysis of EGG's to predict the onset of motion sickness. Proc IEEE 9 th Annual Conf of Eng in Med and Biol Society, 1987: 87-90.

16 Nelsen TS, Kohatsu S. Clinical electrogastrography and its relationship to gastric surgery. Am F Surg 1968; 116: 215-22.

17 Sarna SK, Bowes KL, Daniel EE. Post-operative gastric electrical control activity in man. In: Daniel EE, ed. Gastrointestinal motility. Vancouver: Mitchell Press, 1974: 73-83.

18 McIntyre JA, Deitel M, Baida M, Jalil S. The human electrogastrogram at operation: a preliminary report. $\operatorname{Can} \mathcal{F}$ electrogastrogram at

19 Mirrizi N, Scafoglieri U. Optimal direction of the electrogastrographic signal in man. Med Biol Eng Comput 1983; 21 : 385-9.

20 Familoni BO, Kingma YJ, Bowes KL. Noninvasive assessment of human gastric motor function. IEEE Trans Biomed Eng 1987; 34: 30-6.

21 Ramirez W. The FFT fundamentals and concepts. New York: Prentice-Hall, 1985

22 Code CF, Szurszewski JH, Kelly KA, Smith IB. A concept of control of gastrointestinal motility. Handbook of physiology: alimentary canal, Section 6. Vol. 5. Washington DC: American Physiological Society.

23 Plonsey R. Bioelectric phenomena. New York: McGraw-Hill, 1979: 202-9.

24 Kingma YJ, Durdle NG, Bowes KL, Kocylovski M, Szmidt J. Size of electrical oscillating regions in the canine colon. In: Christensen J, ed. Gastrointestinal motility. New York: Raven Press, 1980: 425-31.

25 Kingma YJ. Spectral analysis of gastrointestinal electrical signals. Automedica, 1987: 237-48. 